\title{
Separation/Analysis Rhodamine B by Anion Surfactant/Ionic Liquid Aqueous Two-Phase Systems Coupled with Ultraviolet Spectrometry
}

\author{
Jun Wu, Hao Fu, Xiashi Zhu \\ College of Chemistry \& Chemical Engineering, Yangzhou University, Yangzhou, China \\ Email:xszhu@yzu.edu.cn, zhuxiashi@sina.com
}

Received 15 May 2014; revised 20 June 2014; accepted 8 July 2014

Copyright (C) 2014 by authors and Scientific Research Publishing Inc.

This work is licensed under the Creative Commons Attribution International License (CC BY).

http://creativecommons.org/licenses/by/4.0/

\section{(c) (i) Open Access}

\begin{abstract}
A novel method for the separation/analysis rhodamine B has been described. The ionic liquid (1-tetradecyl-3-methylimidazolium bromide)/anion surfactant (sodium dodecyl sulfate)/NaCl two-phase systems (ATPSs) is presented as a simple, rapid and effective sample pretreatment technique coupled with ultraviolet spectrometry for analysis rhodamine B in soft drink. The effects of parameters on the ATPSs extraction of rhodamine B such as amount of surfactant, ionic liquid and salt, pH, temperature, stabilization and centrifugal time have been studied in details. Under the optimized conditions, the linear range of calibration curve for rhodamine B was 0.05 $7.0 \mu \mathrm{g} \cdot \mathrm{mL}^{-1}$ and the detection limit was $3.2 \mathrm{ng} \cdot \mathrm{mL}^{-1}$. The phase equilibrium and the mechanism of phase separation for ATPSs have been discussed. This method has been applied to the determination of rhodamine $B$ in soft drink.
\end{abstract}

\section{Keywords}

Rhodamine B, Sodium Dodecyl Sulfate, 1-Tetradecyl-3-methylimidazolium Bromide, The Aqueous Two-Phase Systems (ATPSs)

\section{Introduction}

Rhodamine B is an triphenylmethane dye (Figure 1) used in industrial fields, such as textile and foodstuff industry [1] [2], which is harmful if swallowed by human beings and animals, and causes irritation to the skin, eyes and respiratory tract [3]. In many countries, rhodamine B has been banned in food products due to the ha- 


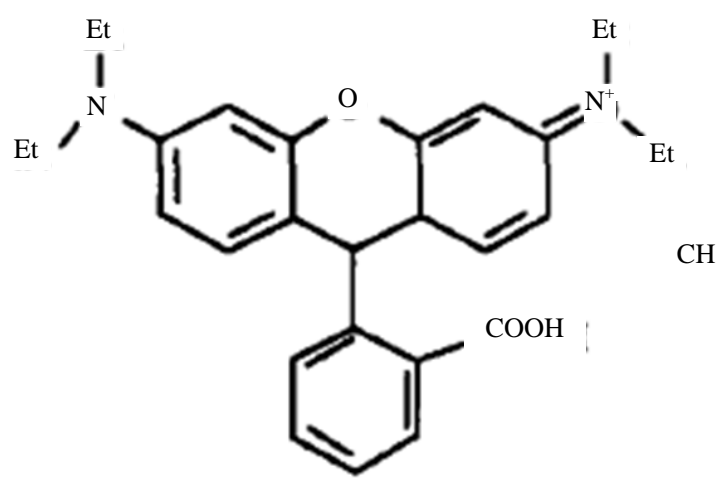

Figure 1. The chemical structure of rhodamine B.

zardous nature and harmful effects [2]. So it has been considered worthwhile to make efforts to develop a simple method for the determination of rhodamine B in real samples.

The direct determination of trace rhodamine B in real samples may not be possible because of low concentrations and matrix interferences, so the preliminary preconcentration and sample clean-up steps are necessary. The methods of preconcentration separation contain high performance liquid hromatography (HPLC) [1]-[4], liquid-liquid extraction (LLE) [5], cloud point extraction (CPE) [6], solid phase extraction (SPE) [3] and so on. LLE is widely applied for the trace metals determination due to its inexpensive cost and easy operation. However, the extraction solvents of LLE are volatile, inflammable and toxic organic solvents which are easy to pollute the environment.

The aqueous two-phase systems (ATPSs) are a kind of LLE technique which is a simple and environmentally friendly separation system because traditional volatile solvents are not used in the whole process. ATPSs are usually composed of two polymers [7], polymer/salt [8], two surfactants [9] or RTILs/salt [10], which have been used in separation and purification of various biological products [11], metal ions [12], dyes [13], drug molecules [14]. However, 1) the high viscidity rich phase may make following determination difficult [14] in the most of polymers-ATPSs; 2) the phase equilibrium processes in surfactants-ATPSs are relatively time-consumming [9]; 3) the RTILs-ATPSs were required a great quantity of ionic liquid and salt [10]. There are the synergistic effect between surfactants and ionic liquids (RTILs) due to their unique characteristics [15] [16]. RTILs and surfactants could form an ordered molecular assembly which not only own the inherent of surfactant but also possess many advantages of RTILs, and achieve the integration of their nature [16]. These features of ordered molecular offer numerous opportunities for the modification of existing extraction processes and for the development of new extraction processes. The ATPSs based on 1-butyl-3-methylimidazolium tetrafluoroborate ([Bmim] $\left.\left[\mathrm{BF}_{4}\right]\right) /$ cationic surfactant (NPTABr) have been reported [17]. But, the ATPSs based on RTILs/anion surfactants seem to be lacking.

In this work, ATPSs based on RTILs (1-tetradecyl-3-methylimidazolium bromide)/anionic surfactant (sodium dodecyl sulfate, SDS)/NaCl were established for separation/analysis trace rhodamine B in real samples coupled with ultraviolet spectrometry at $554 \mathrm{~nm}$. The ATPSs showed a wide range of temperature, quick phase separation with low concentration of the RTILs/salt, which have been successfully applied to the determination of rhodamine B in real samples with satisfactory results.

\section{Experimental}

\subsection{Instrumentation and Reagents}

Ultraviolet spectrophotometer; pHS—25 pH meter (Shanghai, China); Fourier transform infrared spectrometer; High-speed centrifuge (feige); electronic balance (Beijing); magnetic stirring apparatus (Shanghai); conductivity meter (Shanghai).

A standard rhodamine B stock solution of $100.0 \mu \mathrm{g} \cdot \mathrm{mL}^{-1}$ was prepared. The solution was diluted to 10.0 $\mu \mathrm{g} \cdot \mathrm{mL}^{-1}$. Series of HAc-NaAc buffer solutions, $\mathrm{pH} 3.0$ to $8.0,5 \%(\mathrm{w} / \mathrm{v})$ solution of SDS and 3\% solution of RTILs were prepared. All the chemicals were of analytical reagent grade and all solutions were prepared in deionized water. 


\subsection{Procedure}

\subsubsection{Synthesis Method of RTILs}

Briefly, 1-tetradecyl-3-methylimidazolium bromide $\left[\mathrm{C}_{14} \mathrm{mim}\right][\mathrm{Br}]$ was synthesized by adding equal amount (0.05 mol) of n-methylimidazole and 1-bromotetradecane to a $250.0 \mathrm{~mL}$ round bottom flask fitted with reflux condenser. The flask and its content were stirred and heated at $110^{\circ} \mathrm{C}$ for $3 \mathrm{~h}$. Subsequently, the outcome was washed three times with diethyl ether in a separation funnel. Finally, the collected ionic liquid was heated at 40 ${ }^{\circ} \mathrm{C}$ under vacuum last for $4 \mathrm{~h}$ to remove the solvent.

\subsubsection{Phase Diagrams [18]}

The $0.3 \%$ (W/V) RTILs aqueous solution and $0.3 \%$ SDS solution were prepared with $2.0 \% \mathrm{NaCl}$ solution. Samples were prepared by mixing stock-solutions of RTILs and SDS in test tubes at different ratios. The tubes were then immersed in a water bath at temperature $\mathrm{T}=20^{\circ} \mathrm{C}, 40^{\circ} \mathrm{C}, 60^{\circ} \mathrm{C}$ for about $5 \mathrm{~min}$ until phase equilibrium state was attained.

\subsubsection{ATPS Extraction Procedure}

$1.0 \mathrm{~mL}$ standard solutions $\left(10.0 \mu \mathrm{g} \cdot \mathrm{mL}^{-1}\right)$ of rhodamine $\mathrm{B}, 2.0 \mathrm{~mL} \mathrm{pH}=3.8$ buffer solution, $1.0 \mathrm{~mL} 20 \% \mathrm{NaCl}$, $0.6 \mathrm{~mL} \mathrm{3.0 \%} \mathrm{RTILs} \mathrm{and} 1.0 \mathrm{~mL} 5.0 \%$ SDS were transferred into $10.0 \mathrm{~mL}$ centrifuge tube. The mixtures were diluted to the mark with water and shaken thoroughly. Separation of the phases was achieved by centrifugation at $4000 \mathrm{rpm}$ for $4 \mathrm{~min}$. For the separation of two phases, the RTILs/SDS-rich phase was mixed with $1.0 \mathrm{~mL}$ acetate buffer $(\mathrm{pH} 3.8)$ and then diluted to $5.0 \mathrm{~mL}$ with distilled water. Then the absorbance was measured by ultraviolet spectrometry against a reagent blank.

\subsubsection{Sample Preparation}

According to literature [5].

Determination of critical micell concentration (cmc).

According to literature [19].

\section{Results and Discussion}

\subsection{Effect of Temperature on ATPSs}

Phase diagrams of aqueous two-phase systems (ATPSs) composed of RTILs, SDS and salt were constructed at different temperatures, which could reflect the two-phase region of ATPSs clearly.

The effect of temperature on phase equilibrium of RTILs/SDS/NaClt ATPSs were examined at $\mathrm{T}=20^{\circ} \mathrm{C}$, $40^{\circ} \mathrm{C}, 60^{\circ} \mathrm{C}$, respectively. When the temperature increased from $20^{\circ} \mathrm{C}$ to $60^{\circ} \mathrm{C}$, the two-phase region wasn't changed and the ATPSs could be formed with $\mathrm{n}_{\mathrm{RTIL}}: \mathrm{n}_{\mathrm{SDS}}=(2.7: 1)-(3.3: 1)$ at $20^{\circ} \mathrm{C}-60^{\circ} \mathrm{C}$. According to phase diagram, the room temperature $\left(20^{\circ} \mathrm{C}\right)$ was chosen for the following experiments.

\subsection{Effect of the Composition of ATPSs on Extraction Efficiency}

The extraction efficiency of rhodamine B (E\%) could be controlled and optimized with a judicious choice of RTILs/SDS/NaCl ATPSs.

\subsection{Effect of SDS Concentration on the Extraction Efficiency}

The amount of SDS affecting the extraction efficiency of rhodamine B was investigated (Figure 2). E\% was increased gradually with the increase of SDS and achieved maximum when the volume of SDS approached to 1.0 $\mathrm{mL}$, then decreased. The ATPSs could not form with the amount of 5.0\% SDS more than $1.1 \mathrm{~mL}$. So the amount of SDS in the ATPSs was $1.0 \mathrm{~mL}$.

\subsection{Effect of RTILs Concentration on the Extraction Efficiency}

The effect of the amount of RTILs was investigated on the extraction efficiency of rhodamine B and the results were illustrated in Figure 3. As it could be seen, E\% was going up with the RTILs in the range from 0.5 - 0.6 $\mathrm{mL}$, and the maximum appeared at the $0.6 \mathrm{~mL}$, and then decreased. This was because the aqueous two-phase 


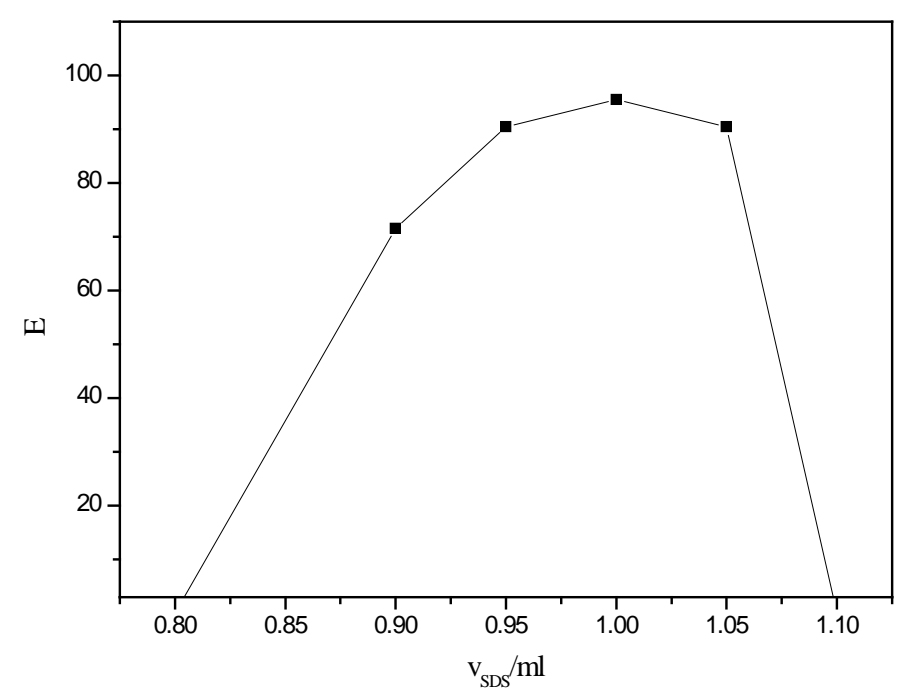

Figure 2. The effect of the amount of surfactant on $\mathrm{E} \%$.

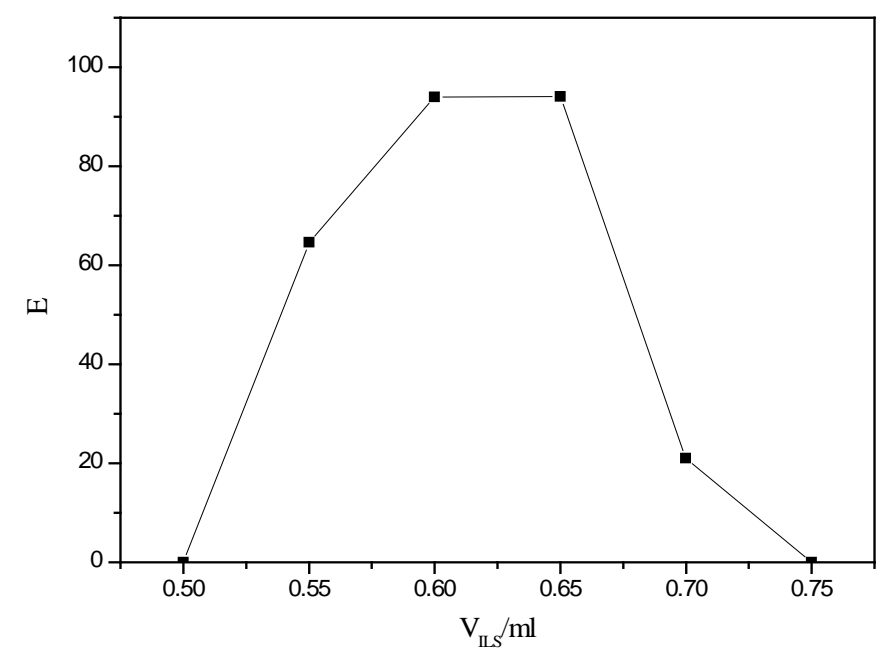

Figure 3. The effect of the amount of RTILs on E\%.

could not formed with the amount of 3.0\% RTILs lower than $0.5 \mathrm{~mL}$ or more than $0.75 \mathrm{~mL}$. In this work $0.6 \mathrm{~mL}$ $3.0 \%(\mathrm{w} / \mathrm{v})$ RTILs was used.

\subsection{Effect of pH on the Extraction Efficiency}

The $\mathrm{pH}$ plays a unique role on ATPSs formation and subsequent extraction. The ATPSs could not formed at $\mathrm{pH}$ $<3.0$ or $\mathrm{pH}>4.4$. The effect of $\mathrm{pH}$ on the extraction efficiency was studied within the $\mathrm{pH}$ range $3.0-4.2$. E\% was at the maximum and wasn't changed when the $\mathrm{pH}$ value was in the range of 3.0 - 4.2. In the paper, $\mathrm{pH} 3.8$ was chosen for the following experiments.

\subsection{Effect of Salt Concentration on the Extraction Efficiency}

The mixture of SDS and RTILs aqueous solution was a homogeneous solution at room temperature. The ATPSs was formed after salt was introduced into the above mixture. Figure 4 showed the effects of $\mathrm{NaCl}$ concentration

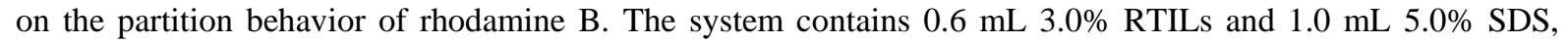
ATPSs could be formed when $20 \% \mathrm{NaCl}$ amount was over $0.7 \mathrm{~mL}$. The experiment results was shown that the extraction efficiency at the maximum and wasn't changed when the amount of $20 \% \mathrm{NaCl}$ was in the range of 1.0 
- $1.2 \mathrm{~mL}$, But the extraction efficiency was quickly decreased when the amount of the salt was beyond $1.2 \mathrm{~mL}$. So the amount of $\mathrm{NaCl}$ in the ATPSs was $1.0 \mathrm{~mL}$.

\subsection{Effect of Stabilization Time and Centrifugal Time}

It was important to select an appropriate stabilization time and centrifugal time that guaranteed the achievement of equilibrium in the ATPSs. The solution was shaken finely for several seconds; the two-phase could be separated by centrifugalization. 4 min centrifugal time was found to be sufficient to establish good extraction efficiency. Thus, 4 min was selected for the subsequent experiments.

\subsection{Effect of Foreign Ions}

The interference of different foreign substrates were discussed in the determination of $1.0 \mu \mathrm{g} \cdot \mathrm{mL}^{-1}$ rhodamine B. The tolerance limits were determined for a maximum error of $\pm 5 \%$ and the results from these studies are collected in Table 1 . The results were collected in Table 1 which was shown the good selectivity of the procedure.

\subsection{Analytical Parameters}

The calibration graph for the determination of rhodamine B was obtained under the best experimental conditions.

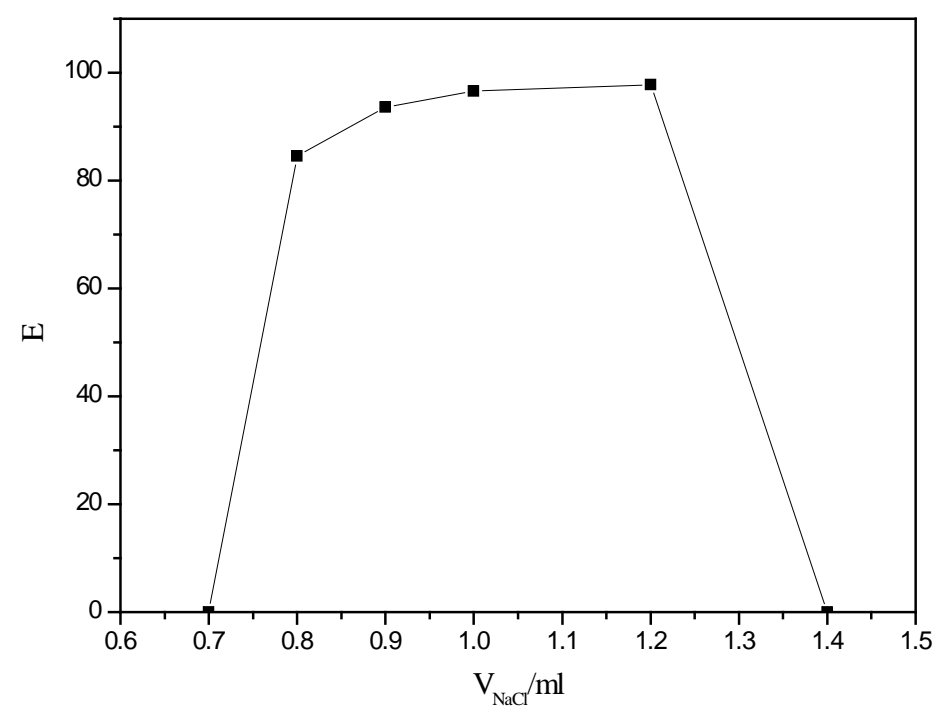

Figure 4. The effect of salt concentration on the extraction efficiency.

Table 1. Tolerance limits of foreign ions for the determination of rhodamine B (results within 5\% error).

\begin{tabular}{cc}
\hline Interferences ions & Tolerance ratio $\left(\mathrm{w}_{1} / \mathrm{w}\right)$ \\
\hline $\mathrm{K}^{+}, \mathrm{Na}^{+}$ & 1000 \\
$\mathrm{Cu}^{2+}$ & 1000 \\
$\mathrm{~Pb}^{2+}$ & 1000 \\
$\mathrm{Cl}^{-}, \mathrm{C}_{2} \mathrm{O}_{4}^{2-}$ & 1000 \\
$\mathrm{Ca}^{2+}$ & 100 \\
Sunset yellow $_{\text {Lemon yellow }}$ & 1000 \\
Carmine & 1000 \\
\hline
\end{tabular}


The results was shown a good linear relationship in the range of $0.05-7.0 \mu \mathrm{g} \cdot \mathrm{mL}^{-1}$. The equation of the analytical calibration curves was $\mathrm{A}=0.52545 \mathrm{c}-0.00528\left(\mathrm{c}: \mu \mathrm{g} \cdot \mathrm{mL}^{-1}\right), \mathrm{r}^{2}=0.9936$. The detection limit (DL) of rhodamine $B$ was determined to be $3.2 \mathrm{ng} \cdot \mathrm{mL}^{-1}$. The relative standard deviations (R.S.D.) was $3.8 \%(\mathrm{n}=4, \mathrm{c}=$ $\left.1.0 \mu \mathrm{g} \cdot \mathrm{mL}^{-1}\right)$.

\subsection{Compared with Some Recent Studies on the Determination of Rhodamine B}

Table 2 compares the characteristic data of the present method with those reported in literatures. Generally, the detection limit obtained by the present method is comparable to those reported method, and the range of linearity and selectivity are better than them.

\subsection{Samples Determination}

The proposed method was applied for the determination of rhodamine B in soft drink. The standard addition method was used and the analytical results and the recovery are presented in Table 3 . The average recoveries of the proposed method were $94.0 \%-102.2 \%$.

\subsection{Discussion of Mechanism of Phase Separation}

The mechanism of the ATPSs (RTILs/SDS/NaCl) on separation rested with two factors: 1) The synergistic effect between the RTILs and SDS; 2) the effect of salting-out.

\subsubsection{The Synergistic Effect between the SDS and RTILs}

The synergistic effect between surfactants and ionic liquids could be reflected on the change of cmc between the RTILs and surfactants. Evaluating the cmc by the measurement of electric conductivity is workable .The plots of electrical conductivity in the different concentration of the solution were showed in Figure 5. The RTILs or RTILs/SDS concentration at which the micellization starts was evident from the change in the slope of the plot. The inflection point was taken as the cmc. The results were listed in Table 4.

As can be seen from Table 4 that the cmc of RTILs, SDS, and SDS/RTILs were $2.5 \mathrm{mmol} \cdot \mathrm{L}^{-1}, 8.4 \mathrm{mmol} \cdot \mathrm{L}^{-1}$ and $0.4 \mathrm{mmol} \cdot \mathrm{L}^{-1}$, respectively. In this work, the molar ratio of RTILs and SDS was 1:3.4. So, the cmc of the clint model should be $5.0 \mathrm{mmol} \cdot \mathrm{L}^{-1}$. There was discrepancy for the $\mathrm{cmc}$ of the mixed solution (SDS/RTILs) in determination value and the clint model value, which demonstrated that there was the synergistic effect between SDS and RTILs. A new ordered molecular assembly was formed.

Table 2. Characteristic performance of some recent studies on the determination of rhodamine B.

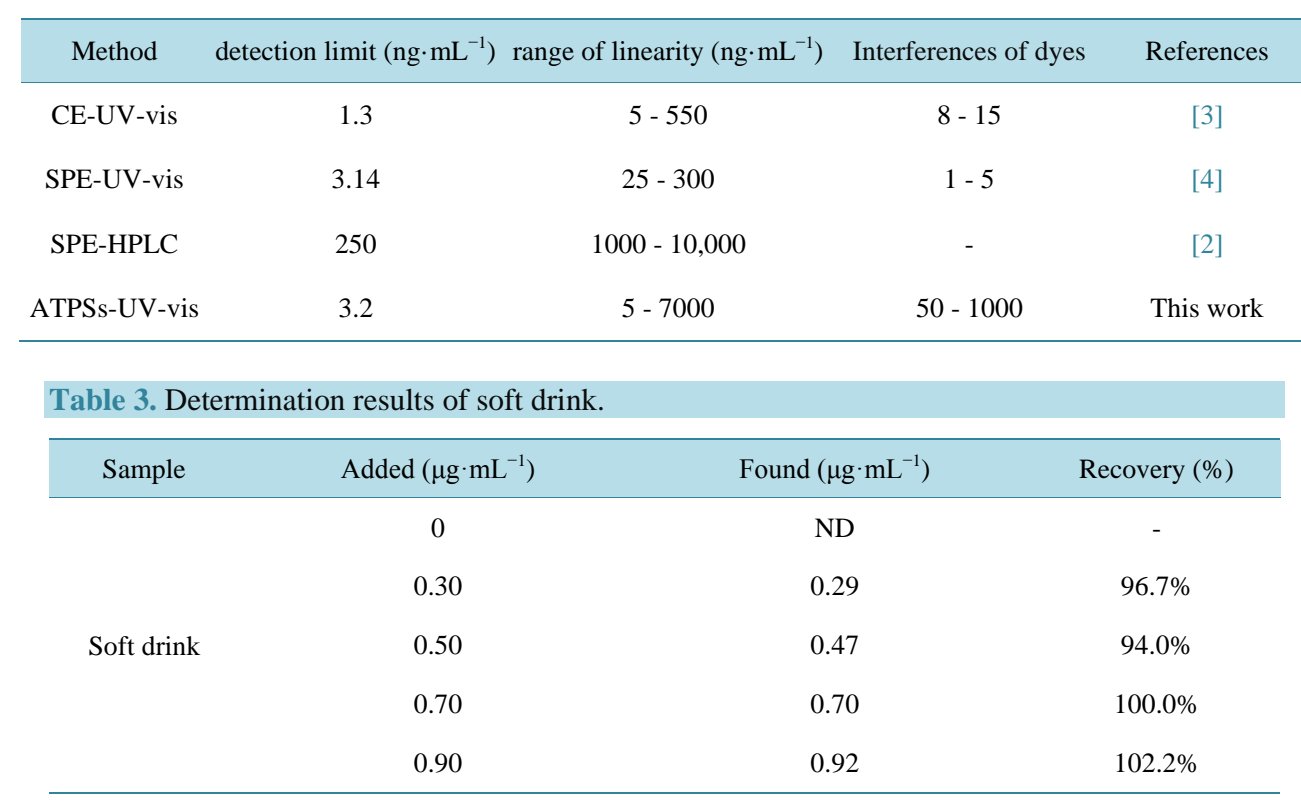




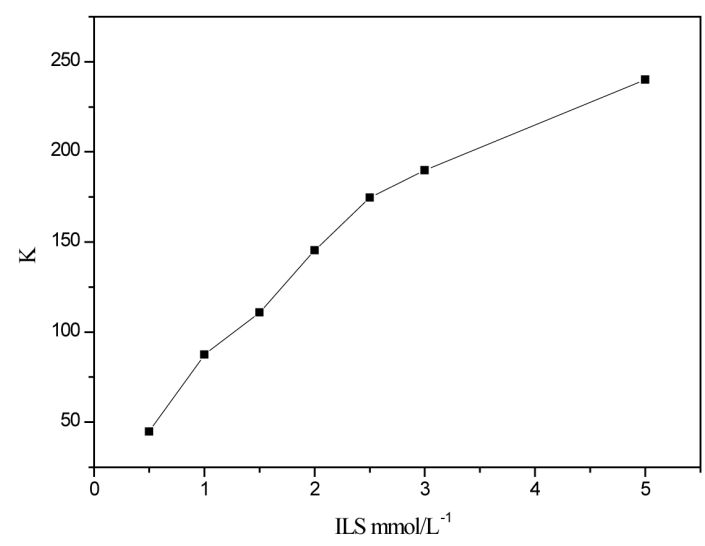

(a)

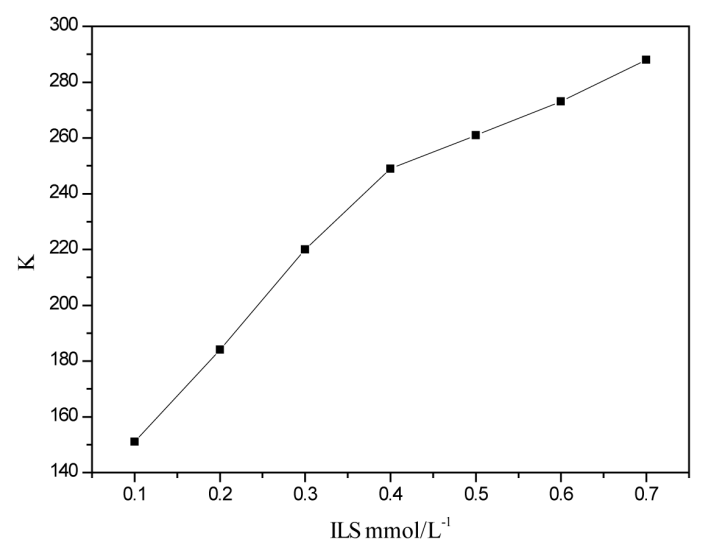

(b)

Figure 5. The plots of electrical conductivity in the different concentration. (a) Electrical conductivity vs the concentration of RTILs; (b) Electrical conductivity vs. the concentration of RTILs/SDS.

\begin{tabular}{c} 
Table 4. cmc of the different medium. \\
\hline Medium \\
\cline { 2 - 3 }
\end{tabular}

${ }^{\mathrm{d} C a l c u l a t e}$ by Clint model [21].

\subsubsection{The Effect of Salting-Out}

The mechanism of RTILs/salt ATPSs formation is under the label of salting-out [10]. When the kosmotropic salt solutions were added in aqueous RTILs solutions, the water molecules close to these ions would be in an electro-constriction state because of their water structuring nature, and their role as solvents to RTILs was reduced [22]. In other words, the formation of RTILs-ATPSs may be considered to be a competition between the hydrophilic polymer and the inorganic salt for the water molecules. The competition is won by the inorganic ions because of their stronger affinity for the water. Compared with RTILs, the molecular assemblies (RTILs/SDS) was more hydrophobic, the water molecules away from the molecular assemblies to the inorganic salt more easier than only RTILs, so the molecular assemblies could form the aqueous two-phase system easier than RTILs.

\section{Conclusion}

The ATPSs consisting of RTILs and SDS are an excellent strategy for extraction of rhodamine B from real samples. This novel extraction technique can be employed in combination with ultraviolet spectrometry as a viable for the quantitative determination of rhodamine B in real samples. The method is characterized with simplicity, rapidity, high selectivity and low cost.

\section{Acknowledgements}

The authors acknowledge the financial support from the National Natural Science Foundation of China (20875082, 21155001) and a Project Funded by the Priority Academic Program Development of Jiangsu Higher Education Institutions and the Foundation of the Excellence Science and Technology Invention Team in Yangzhou University.

\section{References}

[1] Wang, C.X., Han, L., Fang, X.M., Li, B., Wang, M. and Ni, X.L. (2008) Determination of Rhodamine B in Food by 
High Performance Liquid Chromatography-Fluorescence Detection. Anal erotic Instrumentation, 1, 27-30.

[2] Li, X.Y., Li, M., Chen, Q.F., Wei, S.Y., Luo, Y. and Tong, H.J. (2011) Determination of Rhodamine B in Red Wine by Solid Phase Extraction-High Performance Liquid Chromatography. Food Science, 32, 238-242.

[3] Soylak, M., Unsal, Y.E. and Yilmaz, E. (2011) Determination of Rhodamine B in Soft Drink, Waste Water and Lipstick Samples after Solid Phase Extraction. Food and Chemical Toxicology, 49, 1796-1799. http://dx.doi.org/10.1016/j.fct.2011.04.030

[4] Cheng, H., Li, B. and Zhan, C.R. (2010) HPLC-MS/MS Determination of Rhodamine B Residue in Chinese Preserved Sausages. Food Science, 31, 223-225.

[5] Al-Ne'aimi, M.M. and Al-Khuder, M.M. (2013) Synthesis, Characterization and Extraction Studies of Some Metal (II) Complexes Containing (Hydrazoneoxime and Bis-Acylhydrazone) Moieties. Spectrochimica Acta Part A: Molecular and Biomolecular Spectroscopy, 105, 365-373. http://dx.doi.org/10.1016/j.saa.2012.10.046

[6] Pourreza, N., Rastegarzadeh, S. and Larki, A. (2008) Micelle-Mediated Cloud Point Extraction and Spectrophotometric Determination of Rhodamine B Using Triton X-100. Talanta, 77, 733-736. http://dx.doi.org/10.1016/j.talanta.2008.07.031

[7] Sarubboa, L.A., Oliveiraa, L.A., Portob, A.L.F. and Duartec, H.S. (2000) New Aqueous Two-Phase System Based on Cashew-Nut Tree Gum and Poly(ethylene glycol). Journal of Chromatography B: Biomedical Sciences and Applications, 743, 79-84. http://dx.doi.org/10.1016/S0378-4347(99)00516-2

[8] Nguyen, H.L. and Nguyen, T.T.M. (2010) Purification of Extracellular Alpha-Amylase from Bacillus subtilis by Partitioning in a Polyethylene Glycol/Potassium Phosphate Aqueous Two-Phase System. Annals of Microbiology, 60, 623628.

[9] Wang, F., Chen, T., Shang, Y.Z. and Liu, H.L. (2011) Two-Phase Aqueous Systems of Cetyltrimethylammonium Bromide/Sodium Dodecyl Sulfate with and without Polyethylene Glycol. Korean Journal of Chemical Engineering, 28, 923-926. http://dx.doi.org/10.1007/s11814-010-0456-4

[10] Han, J., Wang, Y., Kang, W.B., Li, C.X., San, Y.Y., Pan, J.M. and Xie, X.Q. (2010) Phase Equilibrium and Macrolide Antibiotics Partitioning in Real Water Samples Using a Two-Phase System Composed of the Ionic Liquid 1-Butyl-3methylimidazolium Tetrafluoroborate and an Aqueous Solution of an Inorganic Salt. Microchimica Acta, 169, 15-22. http://dx.doi.org/10.1007/s00604-010-0298-0

[11] Babu, B.R., Rastogi, N.K. and Raghavarao, K.S.M.S. (2008) Liquid-Liquid Extraction of Bromelain and Polyphenol Oxidase Using Aqueous Two-Phase System. Chemical Engineering and Processing: Process Intensification, 47, 83-89. http://dx.doi.org/10.1016/j.cep.2007.08.006

[12] Zhang, T.X., Li., W.J., Zhou, W.J., Gao, H., Wu, J., Xu, G., et al. (2001) Extraction and Separation of Gold (I) Cyanide in Polyethylene Glycol-Based Aqueous Biphasic Systems. Hydrometallurgy, 62, 41-46. http://dx.doi.org/10.1016/S0304-386X(01)00179-7

[13] Pei, Y.C., Wang, J.J., Xuan, X.P., Fan, J. and Fan, M.H. (2007) Factors Affecting Ionic Liquids Based Removal of Anionic Dyes from Water. Environmental Science Technology, 41, 5090-5095.

[14] Li, S.H., He, C.Y., Liu, H.W., Li, K. and Liu, F. (2005) Ionic Liquid-Based Aqueous Two-Phase System, a Sample Pretreatment Procedure Prior to High-Performance Liquid Chromatography of Opium Alkaloids. Journal of Chromatography B, 826, 58-62. http://dx.doi.org/10.1016/j.jchromb.2005.08.005

[15] Lei, S., Zhang, J. and Huang, J.B. (2007) Promotion of the Surface Activity and Aggregation Ability of Sodium Dodecylsulfate in Aqueous Solution by Ionic Liquid 1-Butyl-3-methyl Imidazolium Tetrafluoroborate. Acta PhysicoChimica Sinica, 23, 1657-1661.

[16] Zhu, X.S. and Jiang, R.R. (2011) Determination of Iron(III) by Room Temperature Ionic Liquids/Surfactant Sensitized Fluorescence Quenching Method. Journal of Fluorescence, 21, 385-391. http://dx.doi.org/10.1007/s10895-010-0727-9

[17] Dou, J.L., Fu, S.Z., Wei, Z.B., Liu, J.Q., Yin, B.L., Wei, X.L. and Wu, M.Z. (2010) Dual Aqueous Phase System Formed by Ionic Liquid and Surfactant and Its Performance in Extraction Operations. Chin Surf. Detergent, 40, 246-248.

[18] Zhou, L., Tang, J.N., Chen, Q.Y., Liu, P., Gong, X.Z. and Wei, S.H. (2008) Study of Aqueous Two-Phase System of SDBS/TTAC Mixed Surfactants. Fine Chem, 25, 226-230.

[19] Kumaraguru, N., Santhakumar, K., Arunachalam, S. and Arumugham, M.N. (2006) Synthesis, Characterization and Micellization Behaviour of Some Surface Active Mixed-Ligand Complexes of Cobalt(III). Polyhedron, 25, 3253-3260. http://dx.doi.org/10.1016/j.poly.2006.05.038

[20] Zhang, G.D., Chen, X. and Jing, B. (2006) Ordered Molecular Assembly in Room Temperature Ionic Liquids. Progress in Chemistry, 18, 1085-1091.

[21] Mehta, S.K., Bhawna and Ram, G. (2010) Behavior of Papain in Mixed Micelles of Anionic-Cationic Surfactants Ha- 
ving Similar Tails and Dissimilar Head Groups. Journal of Colloid and Interface Science, 344, 105-111. http://dx.doi.org/10.1016/j.jcis.2009.12.036

[22] Liu, S.P., Zong, Z.M., Wei, Q. and Wei, X.Y. (2010) Study on Organic Compounds in Aqueous Two Phase System Phase Forming and Distribution. Chemical Industry Times, 24, 21-24.

\section{Abbreviations}

cmc: critical micell concentration

SDS: sodium dodecyl sulfate

RTILs: room temperature ionic liquids

ATPSs: aqueous two-phase systems 
Scientific Research Publishing (SCIRP) is one of the largest Open Access journal publishers. It is currently publishing more than 200 open access, online, peer-reviewed journals covering a wide range of academic disciplines. SCIRP serves the worldwide academic communities and contributes to the progress and application of science with its publication.

Other selected journals from SCIRP are listed as below. Submit your manuscript to us via either submit@scirp.org or Online Submission Portal.
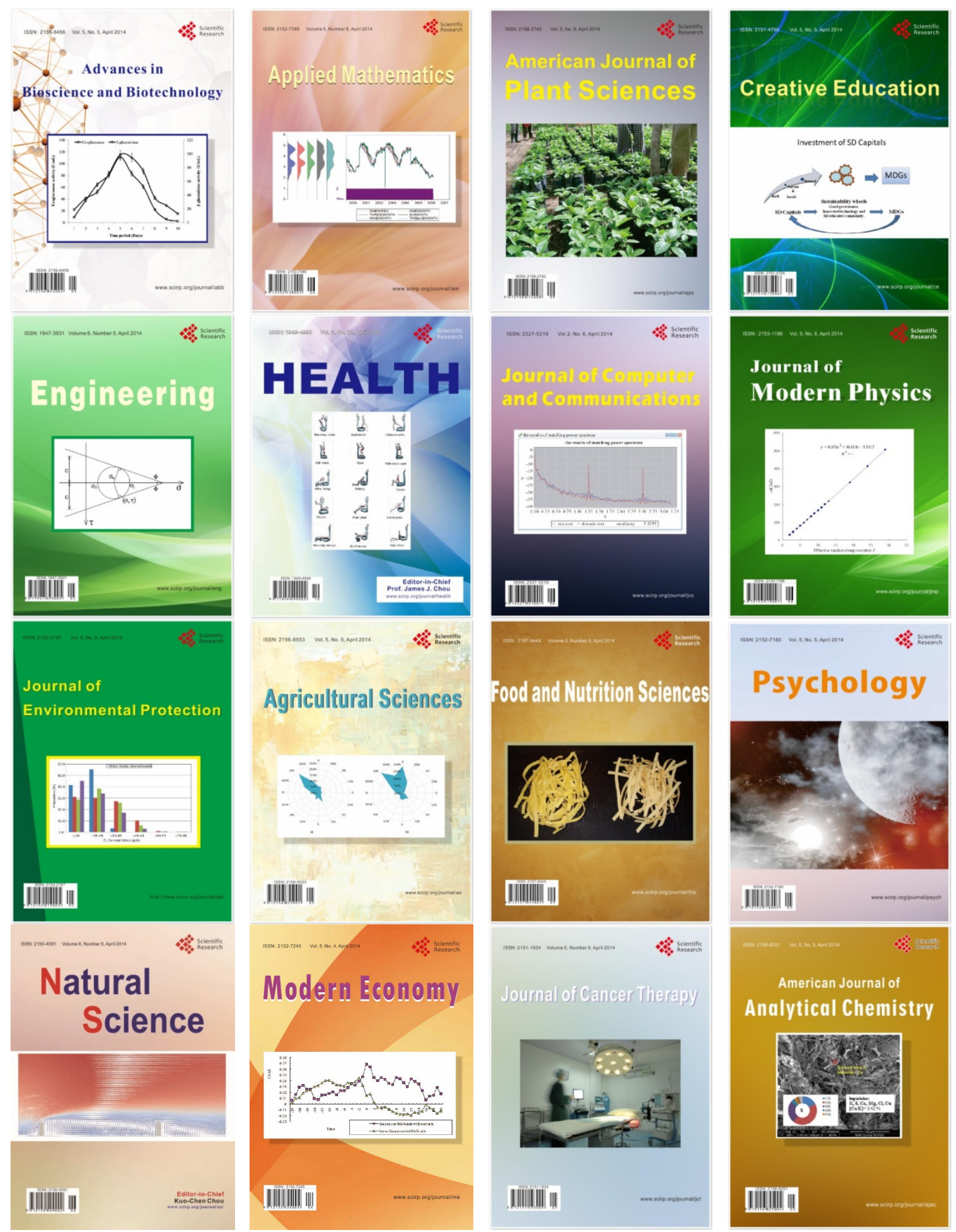